\title{
Benefits of Nature: What We Are Learning about Why People Respond to Nature
}

\author{
Virginia I. Lohr \\ Department of Horticulture and Landscape Architecture, Washington State University
}

\begin{abstract}
People have positive aesthetic, emotional, and physiological responses to nature. Why is this so? The "savanna hypothesis," proposed by Gordon Orians, predicts that some human responses are based on innate knowledge of productive human habitats. To test this, researchers have examined particular aspects of nature that should be associated with productive human habitats to see if they trigger positive responses in people. Tree form has emerged as an important factor in these studies. People prefer looking at trees with spreading forms much more than looking at trees with other forms. Trees with spreading forms existed on the African savanna and were associated with habitats that were good for early human habitation. We have shown that subjects also feel happier when looking at these trees than when looking at other trees or non-tree objects. Color is another variable that might be associated with people's responses to nature. Bright green colors could be an important cue for healthy plants with good nutrient qualities. We measured subjects' physiological responses to tree canopies of various colors and found that all colors were calming, but bright green trees were more calming than other tree colors, including less bright greens and oranges. Adult responses to plants are also influenced by their childhood interactions with nature. We have shown that the more interaction people have with nature as children, the more positive are their attitudes towards nature as adults. These positive responses have been documented in people from a wide range of backgrounds. J Physiol Anthropol 26(2): 83-85, $2007 \mathrm{http}: / /$ www.jstage.jst.go.jp/browse/jpa2

[DOI: $10.2114 / \mathrm{jpa} 2.26 .83$ ]
\end{abstract}

Keywords: childhood, savanna hypothesis, tree color, tree form, trees

\section{Introduction}

A wide range of positive responses to plants and nature have been documented since the 1980s (Relf and Lohr, 2003). This research has shown that people exhibit aesthetic, emotional, and physiological responses to nature. Plants are essential for human survival. They provide food for sustenance, fiber for clothing, fuel for energy, pharmaceuticals for health, and building materials for homes. Historically, they have also provided safety from predators. People have developed in conjunction with nature. It seems reasonable to assume that we would have also developed cues to factors in our surroundings related to nature and our survival. In fact, we know that people respond to daylength, so why not other aspects of nature, such as plants and the weather? Such primitive responses would be associated with mental processing that would be critical for maintaining life in early human existence (Sato, 2005; Watanuki and Kim, 2005).

The range of positive benefits from exposure to trees and nature that has been documented is astounding: stress is lowered, social interactions are improved, recovery from illness is faster, mental fatigue is reduced, attention is increased, productivity is higher, and violence is reduced (Cimprich, 1993; Kuo and Sullivan, 2001; Lohr et al, 1996; Tennessen and Cimprich, 1995; Ulrich, 1984; Wells, 2000). In my lab, we showed that pain tolerance is increased in the presence of plants (Lohr and Pearson-Mims, 2000). We found that perceptions of physical discomfort, measured by having people place their hands in an ice water bath, were lower in a room with plants than in the same room without plants. Perceptions of discomfort were also lower when plants were present than when other decorative objects that were reported to be as visually interesting as the plants were present. This indicated that plants do more than give people something to distract them from the discomfort.

\section{Predicting and Triggering the Response}

Researchers have wondered why people should have such strong associations with plants and nature. One hypothesis, which is being supported by the evidence, is called the "savanna hypothesis" (Orians, 1980; 1986). The savanna hypothesis predicts that the savanna-type landscape, which existed during the development of modern humans, should be 
highly preferred by humans. The savanna environment provided the essentials for human survival: food, trees for protection from predators and the elements, and long, unobstructed views from which to observe both predators and prey. Environmental features that signal high-quality savanna habitats should be preferred by humans.

Researchers are trying to understand what components of nature evoke responses in people. A number of studies have examined people's preferences for particular types of landscapes (e.g. Balling and Falk, 1982; Kaplan and Kaplan, 1989; Orians, 1986). Tree form has emerged as important in a number of studies (Lohr and Pearson-Mims, 2006; Orians and Heerwagen, 1992; Sommer and Summit, 1995). Trees with spreading canopies are generally much preferred over other tree forms (Sommer and Summit, 1995). Trees with such a form (acacia trees) existed in the African savanna and were associated with habitats that were good for human habitation (Orians, 1986). Acacias survive in extremely dry as well as extremely wet areas, but they only assume the wide, spreading form that people prefer when they are growing in areas with average moisture. In areas that would be too dry to be favorable for human habitation, acacias are short and shrubby; in areas that would be too wet, the trees are tall and narrower.

The savanna hypothesis predicts that people like to see trees with spreading forms, because of unconscious, longestablished associations with beneficial habitats. If the hypothesis is correct, then people from a wide range of cultures should prefer this shape. This response has been demonstrated in people in Africa, Asia, Europe, and North America (e.g. Orians, 1986; Sommer, 1997). Our research documented that people also exhibit emotional responses to the spreading tree form (Lohr and Pearson-Mims, 2006). We showed people urban images with non-natural objects or with trees that were columnar, rounded, or spreading. People preferred looking at any scene with a tree more than the nontree scenes, and the scenes with the spreading tree were the most preferred. People also felt happier when they looked at any of the scenes with trees compared to the non-tree scenes, but the response was strongest to the scenes with the spreading trees.

Orians and Heerwagen (1992) suggested that the condition of the vegetation in an area could signal an area's long-term survival potential. A bright green color, which is associated with healthy plants with good nutrient qualities, could be an important landscape cue for people (Kaufman and Lohr, 2004; Orians and Heerwagen, 1992). A less green or yellowed plant could indicate that it is under environmental stress and thus lacking food quality. In my lab, we measured subjects' physiological responses to tree canopies of various hues and intensities (Kaufman and Lohr, in press). We found that people did respond differently to different colors. All tree colors were calming, but the green that would most closely approximate a healthy tree was more calming than other canopy colors, including less bright greens, reds, and yellows. Yellow, which could indicate severe nutrient deficiency, was among the least calming hues.

Our responses to nature and our surroundings are influenced by both innate and learned components, that is, genotype and phenotype (Balling and Falk, 1982; Miyazaki and Tsunetsugu, 2005). Childhood interactions with nature appear to have strong influences on our responses to plants as adults (Lohr, 2004; Lohr and Pearson-Mims, 2004; Lohr and Pearson-Mims, 2005). Generally, the more interaction that people have with trees, plants, and nature as children, the more positive are their attitudes towards trees as adults. The response is stronger if the interaction is active, such as picking flowers, than if it is passive, such as visiting a park. The positive response has been documented in people from a wide range of demographic and ethnic backgrounds.

\section{Conclusion}

People need plants for their survival. Without plants to harvest sunlight and provide food, we could not live. Research shows that plants also contribute positively to our mental health, improve our physical health, and make our communities safer. An understanding of the importance of plants and how and why people respond to them is becoming widely appreciated. Theoretical understandings of possible phenotypic and genotypic components of these responses are being explored and are yielding useful explanations.

\section{References}

Balling JD, Falk JH (1982) Development of visual preference for natural environments. Environment and Behavior 14(1): 5-28

Cimprich, B (1993) Development of an intervention to restore attention in cancer patients. Cancer Nursing 16: 83-92

Kaplan R, Kaplan S (1989) The experience of nature: a psychological perspective. Cambridge University Press, New York, 9-116

Kaufman AJ, Lohr VI (2004) Does plant color affect emotional and physiological responses to landscapes? Acta Horticulturae 639: 229-233

Kaufman AJ, Lohr VI (n.d.) Does it matter what color tree you plant? Eighth International People-Plant Symposium, Hyogo, Japan (Under review)

Kuo FE, Sullivan WC (2001) Aggression and violence in the inner city: effects of environment via mental fatigue. Environment and Behavior 33: 543-571

Lohr VI (2004) Effect of childhood experiences with nature, including planting trees, on adult understanding of trees in cities. Acta Horticulturae 643: 183-187

Lohr VI, Pearson-Mims CH (2000) Physical discomfort may be reduced in the presence of interior plants. HortTechnology 10: 53-58

Lohr VI, Pearson-Mims CH (2004) The relative influence of childhood activities and demographics on adult appreciation for the role of trees in human well-being. Acta Horticulturae 
639: 253-259

Lohr VI, Pearson-Mims CH (2005) Children's active and passive interactions with plants and gardening influence their attitudes and actions towards trees and the environment as adults. HortTechnology 15: 472-476

Lohr VI, Pearson-Mims CH (2006) Responses to scenes with spreading, rounded, and conical tree forms. Environment and Behavior 38: 667-688

Lohr VI, Pearson-Mims CH, Goodwin GK (1996) Interior plants may improve worker productivity and reduce stress in a windowless environment. J Environmental Horticulture 14: $97-100$

Miyazaki Y, Tsunetsugu Y (2005) A tentative proposal on physiological polymorphism and its experimental approaches. J Physiol Anthropol Appl Human Sci 24: 297-300

Orians GH (1980) Habitat selection: General theory and applications to human behavior. In Lockard JS ed. The evolution of human social behavior. Elsevier, Amsterdam, 49-66

Orians GH (1986) An ecological and evolutionary approach to landscape aesthetics. In Penning-Rowsell EC, Lowenthal D eds. Landscape meanings and values. Allen and Unwin, London, 3-22

Orians GH, Heerwagen JH (1992) Evolved responses to landscapes. In Barkow JH, Cosmides L, Tooby J eds. The adapted mind: evolutionary psychology and the generation of culture. Oxford Univ. Press, New York, 555-579

Relf PD, Lohr VI (2003) Human issues in horticulture. HortScience 38: 984-993
Sato M (2005) The development of conceptual framework in physiological anthropology. J Physiol Anthropol Appl Human Sci 24: 289-295

Sommer R (1997) Further cross-national studies of tree form preferences. Ecological Psychol 9: 153-160

Sommer R, Summit J (1995) An exploratory study of preferred tree form. Environment and Behavior 27(4): 540-557

Tennessen CM, Cimprich B (1995) Views to nature: effects on attention. J Environmental Psychol 15: 77-85

Ulrich RS (1984) View through a window may influence recovery from surgery. Science 224: 420-421

Watanuki S, Kim YK (2005) Physiological responses induced by pleasant stimuli. J Physiol Anthropol Appl Human Sci 24: $135-138$

Wells NM (2000) At home with nature: effects of "greenness" on children's cognitive functioning. Environment and Behavior 32: 775-795

This article was presented at the 8th International Congress of Physiological Anthropology, 2006 (ICPA 2006), in Kamakura, Japan.

Received: September 29, 2006

Accepted: November 28, 2006

Correspondence to: Virginia I. Lohr, Department of Horticulture and Landscape Architecture, Washington State University, Pullman, WA 99164-6414 USA

Phone: 509-335-3101

Fax: 509-335-8690

e-mail: lohr@wsu.edu 